\title{
The psychometric properties of the Hungarian version of the Personality Inventory for DSM-5 in a clinical and a community sample
}

\author{
Eszter Labancz ${ }^{1,2}$ (D) Katalin Balázs ${ }^{3}$ • Ildikó Kuritárné Szabó ${ }^{1,2}$ \\ Published online: 12 June 2020 \\ (C) The Author(s) 2020
}

\begin{abstract}
The alternative dimensional model for personality disorders characterizes the individual on pathological personality traits, which can be measured by the Personality Inventory for DSM-5 (PID-5). Our study focused on the psychometric properties of the Hungarian version of PID-5 in 239 psychiatric patients and 226 non-clinical participants. The distribution of gender, age, and educational level were the same in the two samples. In the clinical sample, we examined the assumed unidimensionality of the 25 facets. The results of the exploratory factor analysis for five factors indicated the supposed five-factor structure. The convergent validity was studied by correlations with Big Five Inventory. The PID-5 domains showed moderate or strong correlation with the domains of Big Five except for Psychoticism. The comparison of the clinical and non-clinical samples revealed that psychiatric patients had a higher score on all pathological facets and domains, except for the domain of Antagonism with all its related facets, and the facet of Risk Taking. As a whole, we recommend the use of the Hungarian version of the PID-5 in research and clinical practice.
\end{abstract}

Keywords PID-5 · Psychometric properties · Alternative model of personality disorders $\cdot$ Personality traits $\cdot$ Psychiatric patients Community sample

\section{Introduction}

Since its publication, a number of criticisms has been formulated against the personality disorder classification presented in the fourth edition of the Diagnostic and Statistical Manual of Mental Disorders (DSM-IV; American Psychiatric Association [APA] 2000) (e.g., Clark 2007; Trull and Durrett 2005). Many researchers are of the opinion that clinical reality is better reflected in the dimensional theories applied in academic personality psychology starting from the

Electronic supplementary material The online version of this article (https://doi.org/10.1007/s12144-020-00831-z) contains supplementary material, which is available to authorized users.

Eszter Labancz

labancz.eszter@sph.unideb.hu

1 Department of Behavioural Sciences, University of Debrecen, Debrecen, Hungary

2 Doctoral School of Health Sciences, University of Debrecen, Debrecen, Hungary

3 Institute of Psychology, University of Debrecen, Debrecen, Hungary second half of the twentieth century (e.g., Allport 1961; Eysenck 1970). Frances (1993) stated already 20 years prior to the DSM-5 (APA 2013a), that in the diagnosis of personality disorders the question is not whether there is need for the application of the dimensional model, but simply when it would be applied, and which model would be adequate for this purpose. The representatives of the dimensional approach developed a new personality disorder model, which was published in 2013, in the section entitled "Emerging Measures and Models" of DSM-5, while the official diagnoses are still given by categorical classification.

The alternative personality disorder model found in Section III of DSM-5 defines a new general criteria list for personality disorders, where criterion A assesses the severity of impairment in self- and interpersonal function, whereas criterion $\mathrm{B}$ describes the presence of pathological personality traits, that is the type of impairment (APA 2013a). In order to measure these personality traits, the Personality and Personality Disorders workgroup members and advisors generated a list of 37 facets that on the basis of literature were considered clinically significant. The exploratory factor analysis made it clear that the 37 facets can be subsumed into a more favorable structure comprising 25 facets, that gather in 5 
domains: Negative Affectivity, Detachment, Antagonism, Disinhibition, and Psychoticism. To measure these domains and facets, the Personality Inventory for DSM-5 (PID-5) was developed, which is a self-report questionnaire consisting of 220 items, which can be scored by the respondents on a 4point Likert-type scale to what extent the items are true for them (Krueger et al. 2012).

The PID-5 questionnaire was aimed at the measurement of pathological personality traits (Krueger et al. 2012), therefore its primary target group is clinical populations (Gutiérrez et al. 2017). However, most research to date has used convenience sampling, based typically on student samples from North America (Bach et al. 2018). To our knowledge, the PID-5 questionnaire has been translated into 12 languages so far (Italian, Dutch, German, Danish, French, Norwegian, Spanish, Arabic, Portuguese, Czech, Polish, Persian) and validated since 2013. Among these, it was only the German (Zimmermann et al. 2014), the Danish (Bach et al. 2018; Bo et al. 2016), the Spanish (Gutiérrez et al. 2017), the Portuguese (Pires et al. 2019), and the Czech (Riegel et al. 2018) researchers, who worked on a mixed sample consisting of both general populations and psychiatric patients; the Dutch specialists investigated the psychometric properties of the questionnaire separately in clinical (Bastiaens et al. 2016) and nonclinical (De Fruyt et al. 2013) samples. It is necessary for the reliability and validity of the PID-5 questionnaire to be investigated in clinical and non-clinical samples in as many languages and cultures as possible, thus facilitating the switch to the dimensional approach in personality disorders, and consolidating the use of this measure in clinical practice (Bo et al. 2016).

The five PID-5 domains defined in the dimensional personality model of DSM- 5 can be regarded as maladaptive variants of the domains of the Five-Factor Model (FFM) (Trull 2012), meaning that the domains of PID-5 provide information on the maladaptive endpoint of personality dimensions, whereas FFM domains carry information about the adaptive endpoint (Suzuki et al. 2015). Several studies have confirmed this idea: a strong positive correlation was found between Negative Affectivity and Neuroticism, and a strong negative correlation between Detachment and Extraversion, Antagonism and Agreeableness, Disinhibition and Conscientiousness (Few et al. 2013; Quilty et al. 2013; Zimmermann et al. 2014). However, there have been inconsistent results regarding the relationship between Psychoticism and Openness $(\mathrm{r}=.02$, (Quilty et al. 2013); $r=.31$, (Strus et al. 2017)). The domain of Psychoticism includes quasi psychotic experiences and behavioral characteristics of schizotypal personality disorder (Trull 2012).

The aim of the present research was the Hungarian adaptation of the PID-5 questionnaire. In addition to the investigation of the psychometric properties and the assumed fivefactor structure, the study also evaluated the reliability of the individual domains and facets, convergent validity, and concurrent validity. The convergent validity of the domains was investigated by the correlation with the relevant domains of the Big Five Inventory (BFI), while concurrent validity was estimated on the basis of differences between clinical and nonclinical samples. To our knowledge, this is the first study to investigate these psychometric properties in clinical and nonclinical samples having the same distribution of gender, age, and educational level.

\section{Method}

\section{Participants and Procedures}

Our study was based on psychiatric patients $(n=239)$ and community-dwelling participants, who were self-reportedly not suffering from any mental disorder $(n=226)$.

The clinical sample comprised psychiatric patients from inpatient care and day hospital care. Age between 18 and 60 was the inclusion criterion; the exclusion criterion was the presence of acute psychotic symptoms, or a diagnosis of intellectual disability, or dementia. Each questionnaire was administered in the presence of the investigator (first author) or a trained psychologist. The number of psychiatric patients according to gender was proportionate: $51.9 \%$ women $(n=124)$, with a mean age of 43.7 years $(\mathrm{SD}=11.8)$. The distribution of the educational level was as follows: primary school education or lower $-12.6 \%$, secondary school education $-68.2 \%$, and tertiary education $-19.2 \%$ of the patients. The 239 psychiatric patients had 592 known diagnoses at the time of the study participation. These diagnoses were clinical diagnoses based on electronic medical records. The most common diagnoses were substance use disorders (29.9\%), mood disorders (24.5\%), and neurotic, stress-related and somatoform disorders (26\%) according to the ICD-10. $9.6 \%$ of all the diagnoses comprised personality disorders, that means $23.8 \%$ of the psychiatric patients. The patients with substance use disorder mainly had a diagnosis of alcohol abuse and sedatives/ hypnotics abuse. There were 17 patients $(7 \%)$ with only substance use disorder(s) and no other psychiatric disorders in their lifetime based on their medical records.

The non-clinical sample $(n=226)$ consisted of community participants recruited via snowball sampling, who reported themselves as not suffering from any mental disorder. Age between 18 and 60 was the inclusion criterion; the exclusion criterion was any previous or current mental disorder/ psychiatric treatment, or the lack of a large amount of data during the completion of the questionnaires. Study participants responded to the questionnaire package on their own, but $9 \%$ of the non-clinical participants received assistance in completing the survey. $50.4 \%$ of the non-clinical sample were females $(n=114)$, with a mean age of 41.9 years $(\mathrm{SD}=$ 
13.1). Primary school or lower education was the highest attainment in $8 \%$, secondary school education in $68.1 \%$, and tertiary education in $23.9 \%$ of the participants.

Participation in the study was voluntary. Study participants were provided information in line with research ethics guidelines (Szentmiklósi 2011), and gave their written informed consent to research participation. Study participants did not receive any compensation for their participation. The research was conducted in line with the Helsinki Declaration and approved by institutional, regional, and national research authorities.

\section{Measures}

PID-5 PID-5 is a 220-item self-report questionnaire measuring 25 pathological facets and 5 domains: Negative Affectivity, Detachment, Antagonism, Disinhibition, and Psychoticism (Krueger et al. 2012). The items are scored on a 4-point Likertscale $(0=$ very false or often false, $3=$ very true or often true $) .4$ to 14 items are related to each facet. The domain scores were calculated from the average scores of specific triplets of facets in line with the original PID-5 document (APA 2013b). The original questionnaire was translated into Hungarian by the researchers of the Department of Behavioral Sciences of the University of Debrecen, Ildikó Kuritárné Szabó, Zita Fekete, and Eszter Labancz. The back-translation into English was done by a professional Hungarian-English translator. The consistency of the two English versions was evaluated by a native Englishspeaking clinical psychologist. We revised the discrepancies resulting from translation and finalised the Hungarian version of the PID-5.

BFI For the evaluation of convergent validity, we used the Hungarian version of the Big Five Inventory (BFI; BenetMartinez and John 1998), as it is suitable to measure normal personality. This is a 44-item self-report questionnaire, which measures the domains of the Big Five, that is Neuroticism, Agreeableness, Extraversion, Conscientiousness, and Openness. All the items start with the formula "I see Myself as Someone Who..." and the respondents must indicate on a 5point Likert-scale whether they Disagree strongly $(=1)$, Neither agree nor disagree (=3), or Agree strongly (=5) with the item.

\section{Statistical Analysis}

Data analysis was performed using RStudio (RStudio Team 2015) statistical software.

Chi-square test was used to compare the distribution of gender and level of education of the two samples. As the age variable did not follow a normal distribution, MannWhitney test was applied to compare the age of the two groups.
Relying on the domain calculation standards (APA 2013b), 15 facets contribute to the PID domains. We examined the latent structure composed of 15 facets by fitting confirmatory factor analysis on the clinical sample's data. When confirmatory factor analysis was applied including the 15 facets and five domains, two approaches were followed. First, a square root transformation of the skewed items was applied in order to approach normal distribution. Afterwards, a CFA model was fitted using robust ML estimation. Second, the variables were used without any transformation (in order to reduce potential bias caused by transformation). As confirmatory factor analysis did not approve the assumed latent structure of facet total scores, explanatory factor analysis (with CF-varimax rotation, ML estimation, and for non-normal continuous variables in "EFAutilities" package) was used to reveal actual latent structure shaped by the facets.

Testing the unidimensionality of the facets by CFA, polychoric correlation matrices were used as an input and robust weighted least-square estimations were applied, considering that the type of data is ordinal.

We relied primarily on fit indices and also examined fit results for the individual items. CFI (Bentler 1990) and TLI scores above 0.9 indicate good fit (Marsh et al. 2004). RMSEA (Awang 2012) and SRMR scores (Hu and Bentler 1999) indicate acceptable fit below 0.08 .

As a reliability measure, Cronbach's alpha was calculated for the facets and the domains. To estimate convergent validity, Spearman's rank correlation was calculated among PID-5 domains and BFI dimensions. Concurrent validity was investigated by comparing the non-clinical and the clinical sample applying Mann-Whitney U-test.

\section{Results}

The clinical and the non-clinical sample did not differ in gen$\operatorname{der}\left(\chi^{2}(1)=0.097, p=.756\right)$, or educational level distributions $\left(\chi^{2}(2)=3.535, p=.171\right)$. No significant discrepancy was found $(\mathrm{U}=28,947.5, p=.180)$ between the age of the clinical $(\mathrm{Mdn}=46)$ and the non-clinical sample $(\mathrm{Mdn}=45)$.

As PID-5 is relevant mainly for clinical practice, we relied on the results of the clinical sample during the analyses. Therefore, in case of the non-clinical sample we only provided the fit indices of the unidimensional confirmatory factor analyses fitted for each facet, the Cronbach's alpha values, as well as the mean, median, and standard deviation values of the facets and domains.

The reliability of facet scores was estimated using the Cronbach's alpha values. Item 177 from the facet of Suspiciousness was removed, as based on the reliability analyses this item showed a very low item total correlation in the facet of Suspiciousness $(r=.23$ in the clinical and $r=.0 .01$ in the non-clinical sample). Even looking at the Spearman's rank 
correlations of the facet items, item 177 did not correlate with four items out of six from its facet in the clinical sample (the highest correlation was rho $=.24$ with the remaining items), and with none of the facets in the non-clinical sample. The item 177 seemed to be an outlier. Item 177 is a reversed item, stating that "I rarely feel that people I know are trying to take advantage of me".

The obtained value indicated high reliability in the clinical sample; facet values ranged from .69 to .93, except for the Restricted Affectivity facet (.57). All domains indicated high reliability with values ranging from .75 to .81 . In the nonclinical sample, reliability values were between .69 and .93, with the exception of Suspiciousness (.64) and Restricted Affectivity (.63), which indicated moderate reliability. All domains indicated high reliability in the non-clinical sample as well, with values ranging from .79 to .84 .

For the examination of the latent structure of the data, confirmatory factor analyses were applied. A CFA with a threelevel model could not have been estimated given the sample size, therefore the underlying structure was assessed in two steps. We fitted unidimensional confirmatory factor analyses facet by facet, which seemed to be a common method among PID-5 adaptations (e.g., Riegel et al. 2018; Roskam et al. 2015; Zimmermann et al. 2014). In these analyses, considering that the data are ordinal type, polychoric correlation matrices were used as an input and robust weighted least-square estimations were applied (applying 'lavaan' package). The results by facets are shown in Table 1.

In the clinical sample, the model did not fit by the chisquare test in 23 facets, but as it is known, this is the strictest fit index. Generally, CFI (except for two facets, values were between .90 and 1.00), TLI (except for four facets, values were between .91 and 1.01), RMSEA indices (except for ten facets, values were between .00 and .08), and SRMR (except for two facets, values were between .01 and .08) tended to show good fit.

The CFAs for Hostility, Restricted Affectivity, Manipulativeness, and Risk Taking suggested multidimensional structure, since three out of five fit indices showed inadequate model fit. Hostility furcated into three factors: frequent angry feelings (e.g., ,, 38. I am easily angered. '), mean, nasty, and vengeful behavior (e.g., ,, 32. I can be mean when I need to be."), and irritability (e.g., ,, 188. It makes me really angry when people insult me in even a minor way.").

Restricted Affectivity split into four factors: constricted emotional expression (e.g., ,, 101. People tell me it's difficult to know what I'm feeling."), inhibition of strong emotions (e.g., ,,91. I don't show emotions strongly. ”), and indifference and aloofness (e.g., ,,184. I don't react much to things that seem to make others emotional.").

Manipulativeness bifurcated into usage of charm, glibness, and ingratiation (e.g., ,, 125. I can certainly turn on the charm if I need to get my way. "), and control and influencing (e.g.,
,107. I'm good at making people do what I want them to do.").

Risk Taking split into four factors: risk avoidance (e.g., „87. I avoid anything that might be even a little bit dangerous."), denial of the reality of personal danger (e.g., „,195. I don't think about getting hurt when I'm doing things that might be dangerous."), recklessness (e.g., ,,69. When I want to do something, I don't let the possibility that it might be risky stop me. "), and engagement in risky activities (e.g., ,, 67. I like to take risks. "). Although our results showed that these facets had more complex structures, we examined the content of each factor, and found these factors fitted the definition of facets.

In agreement with the commonly used scoring algorithm of the PID domains (APA 2013b), we fitted a model with five dimensions and 15 facets. Considering all facet variables and the clinical sample, ten variables showed normal distribution based on Kolmogorov-Smirnov tests; five variables differed modestly, and ten were skewed. Focusing only on the 15 facet variables, three of them showed normal distribution based on Kolmogorov-Smirnov tests; two variables differed modestly from the normal distribution, and ten were skewed.

When confirmatory factor analysis was applied including only the 15 facets and five domains, two methods were implemented. First, the skewed items were transformed, in order to approach normal distribution. Aiming normal distribution, the square root transformation seemed more suitable than the log-transformation on these data. A CFA model was fitted using robust ML estimation on the transformed variables, and the results indicated that the model did not fit on the data $(\chi 2(80)=379.542, p<.001, \mathrm{CFI}=.807, \mathrm{TLI}=.746$, RMSEA $=.136, \mathrm{p}<.001, \mathrm{SRMR}=.096)$.

Second, as transforming the variables may have implications for the analyses, the former analysis was repeated with the original variables. The results indicated inadequate model fit again $(\chi 2(80)=410.251, p<.001, \mathrm{CFI}=.790, \mathrm{TLI}=.724$, $\mathrm{RMSEA}=.143, \mathrm{p}<.001, \mathrm{SRMR}=.103)$.

Therefore, exploratory factor analysis was carried out to examine the relationship between the scores of the individual facets. The factor analysis was applied with oblique, CF-varimax rotation and ML estimation (in „EFAutilities” package). In order to take into account the non-normal distribution of the data, the sandwich method (Ogasawara 1998) was implemented for calculating standard errors for rotated factor loadings and factor correlations. The results of the exploratory factor analysis $(\chi 2(140)=493.458, p<.001)$ are presented in Table 2 . The applied critical value for the factor loading was .35 . Above this value, facets were considered to belong to the particular factor. Applying this approach, the results showed deviation from the expected structure only in a small number of cases. The facet of Risk Taking (.15) and Rigid Perfectionism (-.34) indicated a low loading on the domain of Disinhibition. The facet of Hostility should be interpreted both in Negative Affectivity and in 
Table 1 Unidimensional confirmatory factor analysis fit indices and Cronbach's alpha values of the PID-5 facets in the clinical and the non-clinical sample

\begin{tabular}{|c|c|c|c|c|c|c|c|c|c|}
\hline Sample & Facet & $x^{2}$ & df & $\mathrm{p}$ & CFI & TLI & RMSEA & SRMR & $\alpha$ \\
\hline Clinical & Emotional Lability & 54.34 & 14 & $<.001$ & .96 & .93 & .11 & .07 & .78 \\
\hline Non-clinical & & 82.44 & 14 & $<.001$ & .93 & .90 & .15 & .08 & .78 \\
\hline Clinical & Anxiousness & 57.10 & 27 & .001 & .99 & .99 & .07 & .03 & .90 \\
\hline Non-clinical & & 144.22 & 27 & $<.001$ & .96 & .94 & .14 & .07 & .87 \\
\hline Clinical & Separation Insecurity & 45.49 & 14 & $<.001$ & .97 & .95 & .10 & .07 & .78 \\
\hline Non-clinical & & 61.87 & 14 & $<.001$ & .94 & .90 & .12 & .07 & .76 \\
\hline Clinical & Perseveration & 51.25 & 27 & $<.01$ & .98 & .97 & .06 & .05 & .78 \\
\hline Non-clinical & & 32.98 & 27 & $<.05$ & .99 & .98 & .05 & .04 & .82 \\
\hline Clinical & Submissiviness & 0.85 & 2 & .65 & 1.00 & 1.01 & .00 & .01 & .77 \\
\hline Non-clinical & & 12.99 & 2 & $<.01$ & .98 & .95 & .16 & .05 & .77 \\
\hline Clinical & Hostility & 185.23 & 35 & $<.001$ & .90 & .87 & .14 & .10 & .82 \\
\hline Non-clinical & & 137.15 & 35 & $<.001$ & .94 & .92 & .12 & .08 & .85 \\
\hline Clinical & Depressivity & 274.43 & 77 & $<.001$ & .96 & .95 & .10 & .08 & .91 \\
\hline Non-clinical & & 410.57 & 77 & $<.001$ & .92 & .91 & .14 & .12 & .88 \\
\hline Clinical & Suspiciousness & 17.86 & 9 & $<.05$ & .97 & .96 & .06 & .05 & .69 \\
\hline Non-clinical & & 28.31 & 9 & .001 & .92 & .87 & .10 & .06 & .64 \\
\hline Clinical & Restricted Affectivity & 54.27 & 14 & $<.001$ & .83 & .74 & .11 & .08 & .57 \\
\hline Non-clinical & & 63.68 & 14 & $<.001$ & .84 & .76 & .13 & .09 & .63 \\
\hline Clinical & Withdrawal & 67.97 & 35 & .001 & .99 & .98 & .06 & .05 & .87 \\
\hline Non-clinical & & 150.18 & 35 & $<.001$ & .96 & .95 & .12 & .07 & .88 \\
\hline Clinical & Anhedonia & 36.23 & 20 & $<.05$ & .99 & .99 & .06 & .04 & .85 \\
\hline Non-clinical & & 28.53 & 20 & .10 & .99 & .99 & .04 & .04 & .80 \\
\hline Clinical & Intimacy Avoidance & 13.90 & 9 & .13 & 1.00 & 1.00 & .05 & .03 & .85 \\
\hline Non-clinical & & 29.78 & 9 & $<.001$ & .98 & .96 & .10 & .05 & .79 \\
\hline Clinical & Manipulativeness & 42.74 & 5 & $<.001$ & .94 & .87 & .18 & .07 & .77 \\
\hline Non-clinical & & 75.24 & 5 & $<.001$ & .84 & .69 & .25 & .13 & .69 \\
\hline Clinical & Deceitfulness & 83.41 & 35 & $<.001$ & .98 & .97 & .08 & .06 & .87 \\
\hline Non-clinical & & 123.10 & 35 & $<.001$ & .96 & .95 & .11 & .07 & .82 \\
\hline Clinical & Grandiosity & 23.37 & 9 & $<.01$ & .98 & .96 & .08 & .05 & .75 \\
\hline Non-clinical & & 47.97 & 9 & $<.001$ & .94 & .90 & .14 & .08 & .73 \\
\hline Clinical & Attention Seeking & 65.87 & 20 & $<.001$ & .97 & .96 & .10 & .07 & .81 \\
\hline Non-clinical & & 122.26 & 20 & $<.001$ & .92 & .89 & .15 & .10 & .77 \\
\hline Clinical & Callousness & 130.27 & 77 & $<.001$ & .97 & .97 & .05 & .07 & .85 \\
\hline Non-clinical & & 155.87 & 77 & $<.001$ & .98 & .98 & .07 & .06 & .86 \\
\hline Clinical & Irresponsibility & 23.89 & 14 & $<.05$ & .98 & .97 & .06 & .05 & .73 \\
\hline Non-clinical & & 37.13 & 14 & .001 & .96 & .93 & .09 & .07 & .69 \\
\hline Clinical & Impulsivity & 19.05 & 9 & $<.05$ & .99 & .98 & .07 & .04 & .78 \\
\hline Non-clinical & & 10.38 & 9 & .32 & 1.00 & 1.00 & .03 & .03 & .75 \\
\hline Clinical & Distractibility & 62.00 & 27 & .001 & .98 & .97 & .07 & .05 & .86 \\
\hline Non-clinical & & 73.01 & 27 & $<.001$ & .97 & .96 & .09 & .06 & .83 \\
\hline Clinical & Risk Taking & 315.45 & 77 & $<.001$ & .87 & .85 & .11 & .09 & .86 \\
\hline Non-clinical & & 406.27 & 77 & $<.001$ & .74 & .70 & .14 & .12 & .81 \\
\hline Clinical & Rigid Perfectionism & 83.67 & 35 & $<.001$ & .95 & .93 & .08 & .07 & .78 \\
\hline Non-clinical & & 109.30 & 35 & $<.001$ & .94 & .92 & .10 & .07 & .83 \\
\hline Clinical & Unusual Beliefs and Experiences & 69.35 & 20 & $<.001$ & .93 & .91 & .10 & .08 & .75 \\
\hline Non-clinical & & 32.83 & 20 & $<.05$ & .99 & .98 & .05 & .05 & .78 \\
\hline Clinical & Eccentricity & 231.33 & 65 & $<.001$ & .97 & .96 & .10 & .05 & .93 \\
\hline Non-clinical & & 268.96 & 65 & $<.001$ & .99 & .95 & .12 & .06 & .93 \\
\hline Clinical & Cognitive and Perc. Dysregulation & 94.41 & 54 & .001 & .97 & .96 & .06 & .07 & .82 \\
\hline Non-clinical & & 102.23 & 54 & $<.001$ & .98 & .97 & .08 & .06 & .88 \\
\hline
\end{tabular}

$\chi^{2}=$ chi-square test, $d f$ degrees of freedom, CFI comparative fit index, TLI Tucker-Lewis index, RMSEA root mean square error of approximation, $S R M R$ standardized root mean residual, $\alpha=$ Cronbach's alpha value

Antagonism; however, it had a factor loading above the critical value in Antagonism (.36) and Disinhibition (.42). There were two more facets that showed their highest loading not on the expected domain; they, however, showed a factor loading above .35 on the expected ones as well. These included the facets of Anhedonia and Perseveration. Although Emotional Lability and Callousness showed their highest loading where expected, they also had significant loadings in other domain.

The results of the exploratory factor analysis showed the correlations among the five factors presented in Table 2. All domains were positively correlated. The values of correlation coefficients ranged from .24 (Antagonism and Disinhibition) to .42 (Negative Affectivity and Psychoticism), while the relationship of the domain of Negative Affectivity $(r=.01)$ and the domain of Detachment $(r=-.04)$ with Antagonism showed no association.

Convergent validity was estimated calculating Spearman's rank correlation values among PID-5 and BFI domains as shown in Table 3. We found a strong, positive correlation between Negative Affectivity and 
Table 2 Factor loadings from the exploratory factor analysis carried out on facet total scores in the clinical sample and factor intercorrelation values

\begin{tabular}{|c|c|c|c|c|c|}
\hline & $\begin{array}{l}\text { Negative } \\
\text { Affectivity }\end{array}$ & Detachment & Antagonism & Disinhibition & Psychoticism \\
\hline Emotional Lability & .46 & -.17 & -.08 & .38 & .29 \\
\hline Anxiousness & .77 & .18 & -.01 & -.01 & .05 \\
\hline Separation Insecurity & .63 & -.08 & .10 & .06 & .05 \\
\hline Perseveration & .37 & .02 & .05 & .26 & .38 \\
\hline Submissiveness & $\underline{.50}$ & .05 & .07 & .14 & -.05 \\
\hline Hostility & .17 & .02 & .36 & .42 & .13 \\
\hline Depressivity &.$\overline{.55}$ & .34 & -.08 & .24 & .11 \\
\hline Suspiciousness &.$\overline{.35}$ & .23 & .27 & -.10 & .24 \\
\hline Restricted Affectivity & -.13 & .67 & .05 & -.10 & .14 \\
\hline Withdrawal & .16 & .76 & .02 & .05 & .04 \\
\hline Anhedonia & .45 & .42 & -.16 & .19 & .02 \\
\hline Intimacy Avoidance & .06 & .63 & -.15 & .02 & .08 \\
\hline Manipulativeness & -.01 & .00 & .87 & .01 & -.07 \\
\hline Deceitfulness & -.04 & .12 & .69 & .32 & .05 \\
\hline Grandiosity & .03 & -.10 & .66 & -.12 & .27 \\
\hline Attention Seeking & .14 & -.29 & .68 & .10 & .11 \\
\hline Callousness & -.14 & .25 & .50 & .36 & .10 \\
\hline Irresponsibility & -.07 & .23 & .32 & .59 & .04 \\
\hline Impulsivity & .16 & -.04 & .10 & .64 & .08 \\
\hline Distractibility & .34 & .21 & -.18 & .43 & .22 \\
\hline Risk Taking & -.23 & -.12 & .40 & .15 & .16 \\
\hline Rigid Perfectionism & .44 & .00 & .31 & -.34 & .24 \\
\hline $\begin{array}{l}\text { Unusual Beliefs and } \\
\text { Experiences }\end{array}$ & -.07 & .05 & .07 & -.19 & .86 \\
\hline Eccentricity & -.01 & .25 & .15 & .24 & .43 \\
\hline $\begin{array}{l}\text { Cognitive and Perc. } \\
\text { Dysregulation } \\
\text { Factor Intercorrelation }\end{array}$ & .05 & .06 & -.13 & .22 & .80 \\
\hline Negative Affectivity & 1.00 & & & & \\
\hline Detachment & .29 & 1.00 & & & \\
\hline Antagonism & .01 & -.04 & 1.00 & & \\
\hline Disinhibition & .34 & .31 & .24 & 1.00 & \\
\hline Psychoticism & .42 & .32 & .30 & .32 & 1.00 \\
\hline
\end{tabular}

Loadings $\geq .35$ are boldfaced. Facets belonging to the same domain are underlined
Neuroticism (rho $=.72, p<.001$ ), a strong, negative correlation between Detachment and Extraversion (rho = $-.71, \mathrm{p}<.001)$, Disinhibition and Conscientiousness (rho $=-.67, p<.001)$, and a moderate, negative correlation between Antagonism and Agreeableness (rho $=-.29$, $\mathrm{p}<.001)$. Significant relationship between Psychoticism and Openness was not found (rho $=-.02, p=.776$ ); Psychoticism showed the strongest relationship with Neuroticism instead (rho $=.40, p<.001$ ).

Furthermore, the relationship between Openness and Psychoticism was investigated in more detail. Spearman's rank correlation was applied to compare the domain of Openness with each item of Psychoticism. Only three items showed significant correlation with correlation coefficient above .20. The item 94 (rho $=.22, p<.001)$ and 194 (rho $=$ $.20, p<.01)$ from the facet of Unusual Beliefs and Experiences had significant positive correlation with Openness, while the item 83 (rho $=-.26, \mathrm{p}<.001)$ from the facet of Cognitive and Perceptual Dysregulation showed significant negative correlation with Openness.

Finally, the concurrent validity of the scale was examined with regard to each domain and facet by comparing the two samples. A modified 0.002 significance level was applied, in order to correct for the increased type 1 error due to the high number of comparisons. Table 4 shows the mean, standard deviation, and median values of the given domain or facet 
Table 3 Spearman's rank correlation values among PID-5 and BFI domains in the clinical sample

\begin{tabular}{|c|c|c|c|c|c|}
\hline Domains & Neuroticism & Extraversion & Agreeableness & Conscientiousness & Openness \\
\hline Negative Affectivity & $.72 * *$ & $-.42 * *$ & -.08 & $-.26 * *$ & $-.27 * *$ \\
\hline Detachment & $.53^{* *}$ & $-.71 * *$ & $-.27 * *$ & $-.27 * *$ & $-.38 * *$ \\
\hline Antagonism & .02 & $.26^{* *}$ & $-.29 * *$ & $-.26^{* *}$ & $.31 * *$ \\
\hline Disinhibition & $.60 * *$ & $-.39 * *$ & $-.37 * *$ & $-.67 * *$ & $-.27 * *$ \\
\hline Psychoticism & $.40^{* *}$ & $-.24 * *$ & $-.27 * *$ & $-.33 * *$ & -.02 \\
\hline
\end{tabular}

$* * \mathrm{p}<.001$

by samples. As the significance of the Mann-Whitney test presented in the last column, also shows, there was a significant difference between the two groups regarding 4 domains and 18 facets. These results confirm the concurrent validity of the PID-5.

\section{Discussion}

There is a growing number of evidence demonstrating that the psychometric properties of the PID-5 questionnaire are adequate. The preparation of the Hungarian version of the PID-5
Table 4 Facet and domain central tendency deviations in the clinical and the non-clinical sample

\begin{tabular}{|c|c|c|c|c|c|}
\hline \multirow[t]{2}{*}{ Domains/facets } & \multicolumn{2}{|l|}{ Clinical } & \multicolumn{2}{|c|}{ Non-clinical } & \multirow[t]{2}{*}{ U-test } \\
\hline & $\mathrm{M}(\mathrm{SD})$ & Mdn & $\mathrm{M}(\mathrm{SD})$ & Mdn & \\
\hline Negative Affectivity & $1.58(.64)$ & 1.62 & $0.93(.49)$ & 0.89 & $42487 * *$ \\
\hline Detachment & $1.08(.64)$ & 1.02 & $0.65(.42)$ & 0.66 & $37695 * *$ \\
\hline Antagonism & $0.71(.53)$ & 0.60 & $0.66(.38)$ & 0.61 & 26801 \\
\hline Disinhibition & $1.04(.56)$ & 0.96 & $0.69(.38)$ & 0.69 & $37146^{* *}$ \\
\hline Psychoticism & $0.90(.55)$ & 0.92 & $0.53(.41)$ & 0.46 & $37723 * *$ \\
\hline Emotional Lability & $1.63(.71)$ & 1.70 & $1.02(.54)$ & 1.00 & $40532 * *$ \\
\hline Anxiousness & $1.72(.84)$ & 1.78 & $0.99(.61)$ & 0.89 & $40488 * *$ \\
\hline Separation Insecurity & $1.40(.75)$ & 1.43 & $0.77(.54)$ & 0.71 & $40031 * *$ \\
\hline Perseveration & $1.33(.63)$ & 1.33 & $0.83(.49)$ & 0.89 & $39290 * *$ \\
\hline Submissiveness & $1.05(.79)$ & 1.00 & $0.67(.54)$ & 0.75 & $34416^{* *}$ \\
\hline Hostility & $1.00(.64)$ & 1.00 & $0.93(.53)$ & 0.90 & 28488 \\
\hline Depressivity & $1.19(.72)$ & 1.07 & $0.58(.45)$ & 0.50 & $40776^{* *}$ \\
\hline Suspiciousness & $1.44(.64)$ & 1.50 & $1.02(.48)$ & 1.00 & $37674 * *$ \\
\hline Restricted Affectivity & $1.20(.53)$ & 1.14 & $0.99(.43)$ & 1.00 & $33240 * *$ \\
\hline Withdrawal & $1.11(.73)$ & 1.10 & $0.68(.52)$ & 0.70 & $36357 * *$ \\
\hline Anhedonia & $1.20(.74)$ & 1.00 & $0.66(.44)$ & 0.62 & $38615^{* *}$ \\
\hline Intimacy Avoidance & $0.95(.82)$ & 0.83 & $0.62(.52)$ & 0.55 & $32392 * *$ \\
\hline Manipulativeness & $0.82(.69)$ & 0.80 & $0.78(.49)$ & 0.80 & 26524 \\
\hline Deceitfulness & $0.61(.59)$ & 0.50 & $0.60(.42)$ & 0.50 & 25052 \\
\hline Grandiosity & $0.69(.60)$ & 0.50 & $0.59(.44)$ & 0.50 & 28488 \\
\hline Attention Seeking & $1.03(.64)$ & 1.00 & $0.85(.46)$ & 0.88 & 31099 \\
\hline Callousness & $0.44(.46)$ & 0.29 & $0.44(.38)$ & 0.36 & 25601 \\
\hline Irresponsibility & $0.80(.59)$ & 0.71 & $0.54(.38)$ & 0.43 & $33332 * *$ \\
\hline Impulsivity & $1.15(.72)$ & 1.00 & $0.83(.52)$ & 0.83 & $33577 * *$ \\
\hline Distractibility & $1.18(.72)$ & 1.11 & $0.69(.46)$ & 0.67 & $37695 * *$ \\
\hline Risk Taking & $1.21(.63)$ & 1.14 & $1.14(.44)$ & 1.14 & 28490 \\
\hline Rigid Perfectionism & $1.57(.62)$ & 1.60 & $1.16(.54)$ & 1.10 & $37808 * *$ \\
\hline Unusual Beliefs and Experiences & $0.79(.61)$ & 0.75 & $0.54(.46)$ & 0.50 & $33162 * *$ \\
\hline Eccentricity & $1.16(.79)$ & 1.08 & $0.67(.54)$ & 0.62 & $37249 * *$ \\
\hline Cognitive and Perceptual Dysregulation & $0.76(.57)$ & 0.67 & $0.44(.40)$ & 0.26 & $37155 * *$ \\
\hline
\end{tabular}

$* * p<.002 .(\alpha=0.05 / 25=0.002)$ 
questionnaire and the investigation of its psychometric properties in clinical and non-clinical samples, were also in line with previous studies. However, to our knowledge, our study is the first to include a clinical and a non-clinical sample having the same distribution of gender, age, and educational level.

The item 177 correlated poorly with Suspiciousness total score, in line with the results of previous study (Fossati et al. 2013), therefore it was removed. During the personally assisted data collection in the clinical sample, research assistants reported that this item often needed further explanation. As the Cronbach's alpha coefficients showed, all domains and facets except for Restricted Affectivity indicated good reliability in the clinical sample. All facets and domains showed good reliability in the non-clinical sample as well, with the exception of Suspiciousness and Restricted Affectivity, which indicated moderate reliability. Previous studies have confirmed that the facets of Suspiciousness and Restricted Affectivity showed lower reliability than expected (Gutiérrez et al. 2017; Lotfi et al. 2018; Pires et al. 2019; Riegel et al. 2018; Roskam et al. 2015; Van den Broeck et al. 2014).

As the use of PID-5 is relevant for clinical practice, we relied on the results of the clinical sample. The confirmatory factor analysis showed that the initially assumed five-factor structure did not fit the data. A possible explanation is that the questionnaire might measure interrelated constructs imbedded in the structure of personality.

The unidimensional confirmatory factor analyses could not confirm clear-cut unidimensionality of the facets. Unidimensionality was questionable on case of four facets: Hostility, Restricted Affectivity, Manipulativeness, and Risk Taking. These facets furcated into maximum four factors. We examined the content of each factor and found these factors fitted the definition of facets. Previous studies also showed that the facet of Hostility (Zimmermann et al. 2014), the facet of Manipulativeness (Zimmermann et al. 2014), and the facet of Risk Taking (Riegel et al. 2018) were multidimensional. The facet of Risk Taking included the risk avoidance factor in our study, which contained only reversed items. This supported the Czech researchers' (Riegel et al. 2018) result, which showed that the reversed items of Risk Taking were related to different patterns of response.

Exploratory factor analysis revealed that in case of Negative Affectivity the facet of Emotional Lability had high factor loading on Disinhibition, which was in line with the results of previous studies (Bastiaens et al. 2016; Bo et al. 2016; Pires et al. 2019; Riegel et al. 2018). A possible explanation is that its items reflect the characteristics of borderline functioning as well. The facet of Perseveration showed the highest factor loading on Psychoticism, while it had a significant factor loading on Negative Affectivity as well. In previous studies, Danish (Bach et al. 2018), Norwegian (Thimm et al. 2017), Polish (Strus et al. 2017), and American (Wright et al. 2012) researchers also published results revealing that
Perseveration showed high factor loading (>.40) on Psychoticism. Perseveration can be interpreted as a rigid coping mechanism of persons with cognitive perceptual dysregulation, who are struggling with everyday tasks. Although they are aware of the lack of efficiency, they find no other way to cope.

Regarding Detachment, it must be highlighted that the facet of Anhedonia showed high factor loading on Negative Affectivity in agreement with previous findings (Pires et al. 2019; Riegel et al. 2018; Roskam et al. 2015). In the Hungarian sample, Anhedonia seemed to go hand in hand with frequent and intense negative emotions.

In case of Antagonism, our results were in line with our expectations. Its facets showed the highest factor loading on their own domain. The facet of Callousness had a significant factor loading on Disinhibition as well, which was consistent with an earlier finding (Gutiérrez et al. 2017). The facet of Hostility must be interpreted both in the domain of Negative Affectivity and Antagonism. In line with the results of previous studies (Bastiaens et al. 2016; Bo et al. 2016; De Fruyt et al. 2013; Gutiérrez et al. 2017; Pires et al. 2019; Roskam et al. 2015; Strus et al. 2017; Thimm et al. 2017; Wright et al. 2012; Zimmermann et al. 2014), Hostility had high loading on Antagonism in our study as well, supporting Griffin and Samuel's (2014) view, who considered the facet of Hostility to show a better fit to Antagonism rather than Negative Affectivity. Furthermore, in our study the facet of Hostility had the highest loading on Disinhibition, in agreement with a previous finding (Riegel et al. 2018). Based on our findings, we suggest that the high factor loadings of the facets of Callousness and Hostility on Antagonism and Disinhibition might indicate that the PID-5 not only shows that these two facets destroy or poison relationships, but highlights the way how these traits manifest: the individual does not intend to control these behaviors, and/or the individual reacts in this way even to small triggers.

Regarding Disinhibition, the facet of Risk Taking showed a negligible factor loading on its own domain and high factor loading on Antagonism, while the facet of Rigid Perfectionism had a relatively low factor loading on its own domain and high factor loading on Negative Affectivity as well. Zimmermann et al. (2014) reported that the replicability of Disinhibition was currently unclear, as the Disinhibition domain may be split into a compulsive and an impulsive part, and the latter may take on an antagonistic or emotionally dysregulated shape. Our results also indicated that behavioral dyscontrol and problems with conscience are represented in the interpersonal space. Being disinhibited and not considering future consequences affect, and are affected by the interpersonal relationships. Behavioral control is an essential component of the adaptive relationship behavior, that also takes into consideration others' interests and future consequences. A lack of the above results in the deterioration of relationship 
quality, which makes partners suffer, and/or makes the persons themselves suffer. Psychoticism produced results that were in line with our expectations.

PID-5 domains correlated as expected. In agreement with other studies (Bach et al. 2018; Lotfi et al. 2018; Zimmermann et al. 2014), the correlation of Negative Affectivity and Detachment with Antagonism showed no association, while one of the highest positive correlations was detected between Negative Affectivity and Psychoticism.

The convergent validity of the PID-5 was estimated using the Big Five Inventory. Our results were largely in line with our expectations. A strong positive correlation was found between Negative Affectivity and Neuroticism, a strong negative relationship was detected between Detachment and Extraversion, Disinhibition and Conscientiousness. A moderately negative correlation was observed between Antagonism and Agreeableness. The latter result may be caused by the fact that the clinical sample produced a surprisingly low score on the domain of Antagonism compared to the other domains. Nevertheless, Antagonism showed one of the strongest associations with Agreeableness. In addition, we found that Agreeableness showed one of the strongest correlations with Disinhibition, which was consistent with earlier findings (Fowler et al. 2017; Quilty et al. 2013).

The domains of Psychoticism and Openness proved to be unrelated in our study except for three items from the domain of Psychoticism, which were correlated with Openness. The facet of Unusual Beliefs and Experiences included two items ("94. I have some unusual abilities, like sometimes knowing exactly what someone is thinking"; "194. I often see unusual connections between things that most people miss."). The third item ("83. I often can't control what I think about.") was in the facet of Cognitive and Perceptual Dysregulation. These three items should not necessarily be understood as having maladaptive meaning compared to the other items of Psychoticism. Thus, our findings were in line with the results of previous studies, which did not reveal correlation between these two domains (Few et al. 2013; Quilty et al. 2013; Sleep et al. 2018; Suzuki et al. 2015). It is noteworthy that several studies found associations between Psychoticism and Openness (Strus et al. 2017; Thomas et al. 2013; Watson et al. 2013; Zimmermann et al. 2014). Further studies are needed to explore the association between these two dimensions.

To ensure comparability of the clinical and non-clinical sample, the distribution of gender, age, and educational level were the same in the two samples. It was found both on PID-5 domain and facet level, that the clinical sample had a higher score than the members of the general population. The two samples were very similar in pattern: the facets under Negative Affectivity and Disinhibition exhibited the highest scores on both clinical and community samples, which was consistent with earlier findings (e.g., Al-Attiyah et al. 2017; De Fruyt et al. 2013; Fossati et al. 2013; Fowler et al. 2017; Pires et al. 2017). The only exception was the domain of Antagonism with all its related facets and Risk Taking, as there was no significant difference between the two groups in these respects. It is noteworthy that the clinical sample produced a surprisingly low score on the domain of Antagonism compared to the rest of the domains, which complied with what Danish researchers had found (Bach et al. 2018). A possible explanation is that its items focus on attitudes and behaviors, which conceptual content is easily recognized by respondents as undesirable; in an attempt to maintain social desirability, they are less willing to admit such attitudes and behaviors. Psychiatric patients seem to be less able to acknowledge their socially non desirable behaviors, whereas they do recognize and acknowledge their subjective suffering, seclusion in relationships, or their tendency to have a weak behavioral control. Presumably, the latter aspects fit better the image of the needy and helpless patient. Since the PID-5 does not have a validity scale, the extent of trustworthiness, while answering the items, cannot be evaluated.

There was no difference between the two samples regarding the score of Risk Taking facet. It is notable that the nonclinical sample produced a surprisingly high score on the Risk Taking facet compared to the other facets, which was consistent with the finding of Danish researchers (Bach et al. 2018). One possible explanation is that the items describe such attitudes and behaviors that the person feels desirable for living a successful life. Items like "I like to take risks" do not have maladaptive meaning by all means.

Our results confirmed the applicability of the dimensional model, since the same dimensions can be used to describe both normal and abnormal personality, with abnormal personality variations placed at the extremes points of the scale. A group with one specific personality disorder would presumably have a profile with a more specific pattern, that is, they would have higher scores on their characteristic facets. Since this study involved patients with various diagnoses, the scores converged towards the mean, thus specific patterns can hardly be seen. Nevertheless, the Hungarian version of PID-5 can distinguish between clinical and non-clinical samples. Our results confirm the concurrent validity, and we recommend using the Hungarian version of the PID-5 in research and clinical practice.

\section{Strengths and Limitations}

One strength of the present study is the inclusion of both clinical and non-clinical samples. It should be emphasized that gender distribution was equal in both clinical and non-clinical groups; we involved people with a large age range and strove 
for heterogeneity in the level of education as well. The distribution of gender, age, and educational level were the same in the two samples, in order to ensure appropriate comparability of the clinical and non-clinical samples as possible.

One of the limitations of our study is that the diagnoses of the psychiatric patients were based on medical records. Due to the relatively low number of patients, the excessive diagnostic heterogeneity, and the large number of comorbid disorders within the group, our study did not intend to explore the characteristic features of the specific diagnostic categories.

Furthermore, we have to admit that the information regarding the psychiatric disorders and treatment of the participants in the non-clinical sample was self-report data. Thus, the nonclinical sample might contain persons with undiagnosed or underreported substance use disorder or other.

Acknowledgements Special thanks to Liselotte Csüri, Noémi Eszenyi, Dóra Kiss and Zsanett Usztics, for their participation in the process of data collection.

Availability of Data All data generated or analysed during this study are included in this published article and its supplementary information files. Code Availability Not applicable.

Author Contributions All authors contributed to the study conception and design. Material preparation, and data collection were performed by Eszter Labancz. Statistical analysis were performed by Katalin Balázs. The first draft of the manuscript was written by Eszter Labancz and Katalin Balázs and all authors commented on previous versions of the manuscript. All authors read and approved the final manuscript.

Funding Information Open access funding provided by University of Debrecen (DE). This research was supported in part by EFOP-3.6.3VEKOP-16-2017-00009 co-financed by EU and the European Social Found. Eszter Labancz received the award.

\section{Compliance with Ethical Standards}

Conflict of Interest The authors declare that they have no conflict of interest.

Ethics Approval All procedures performed in studies involving human participants were in accordance with the ethical standards of the institutional, regional and national research committee and with the 1964 Helsinki Declaration and its later amendments or comparable ethical standards. The study was approved by the Scientific and Research Committee of the Medical Research Council of Hungary.

\section{Consent to Publication Not applicable.}

Informed Consent Informed consent was obtained from all individual participants included in the study.

Open Access This article is licensed under a Creative Commons Attribution 4.0 International License, which permits use, sharing, adaptation, distribution and reproduction in any medium or format, as long as you give appropriate credit to the original author(s) and the source, provide a link to the Creative Commons licence, and indicate if changes were made. The images or other third party material in this article are included in the article's Creative Commons licence, unless indicated otherwise in a credit line to the material. If material is not included in the article's Creative Commons licence and your intended use is not permitted by statutory regulation or exceeds the permitted use, you will need to obtain permission directly from the copyright holder. To view a copy of this licence, visit http://creativecommons.org/licenses/by/4.0/.

\section{References}

Al-Attiyah, A. A., Megreya, A. M., Alrashidi, M., Dominguez-Lara, S. A., \& Al-Sheerawi, A. (2017). The psychometric properties of an Arabic version of the personality inventory for DSM-5 (PID-5) across three Arabic-speaking middle eastern countries. International Journal of Culture and Mental Health, 10(2), 197205. https://doi.org/10.1080/17542863.2017.1290125.

Allport, G. W. (1961). Pattern and growth in personality. New York: Holt, Rinehart, \& Winston.

American Psychiatric Association. (2000). Diagnostic and statistical manual of mental disorders (4th ed.). Washington, DC: American Psychiatric Association.

American Psychiatric Association. (2013a). Diagnostic and statistical manual of mental disorders (5th ed.). Washington, DC: American Psychiatric Association.

American Psychiatric Association (2013b). Online Assessment Measures: The Personality Inventory for DSM-5 (PID-5) - Adults. Retrieved from http://www.psychiatry.org/practice/dsm/dsm5/online-assessment-measures\#Personality.

Awang, Z. (2012). Structural equation modeling using AMOS graphic. Shah Alam: Penerbit Universiti Teknologi MARA.

Bach, B., Sellbom, M., \& Simonsen, E. (2018). Personality inventory for DSM-5 (PID-5) in clinical versus nonclinical individuals: Generalizability of psychometric features. Assessment, 25(7), 815825. https://doi.org/10.1177/1073191117709070.

Bastiaens, T., Claes, L., Smits, D., De Clercq, B., De Fruyt, F., Rossi, G., et al. (2016). The construct validity of the Dutch personality inventory for DSM-5 personality disorders (PID-5) in a clinical sample. Assessment, 23(1), 42-51. https://doi.org/10.1177/1073191115575069.

Benet-Martinez, V., \& John, O. P. (1998). Los Cinco Grandes across cultures and etihnic groups: Multitrait multimethod analyses of the big five in Spanish and English. Journal of Personality and Social Psychology, 75(3), 729-750. https://doi.org/10.1037//0022-3514.75.3.729.

Bentler, P. M. (1990). Comparative fit indexes in structural models. Psychological Bulletin, 107(2), 238-246. https://doi.org/10.1037/ 0033-2909.107.2.238.

Bo, S., Bach, B., Mortensen, E. L., \& Simonsen, E. (2016). Reliability and hierarchical structure of DSM-5 pathological traits in a Danish mixed sample. Journal of Personality Disorders, 30(1), 112-129. https://doi.org/10.1521/pedi_2015_29_187.

Clark, L. A. (2007). Assessment and diagnosis of personality disorder: Perennial issues and an emerging reconceptualization. Annual Review of Psychology, 58, 227-257. https://doi.org/10.1146/ annurev.psych.57.102904.190200.

De Fruyt, F., De Clercq, B., De Bolle, M., Wille, B., Markon, K., \& Krueger, R. F. (2013). General and maladaptive traits in a five-factor framework for DSM-5 in a university student sample. Assessment, 20(3), 295-307. https://doi.org/10.1177/1073191113475808.

Eysenck, H. J. (1970). The structure of human personality. New York: Methuen.

Few, L. R., Miller, J. D., Rothbaum, A. O., Meller, S., Maples, J., Terry, D. P., Collins, B., \& MacKillop, J. (2013). Examination of the section III DSM-5 diagnostic system for personality disorders in an outpatient clinical sample. Journal of Abnormal Psychology, 122(4), 1057-1069. https://doi.org/10.1037/a0034878. 
Fossati, A., Krueger, R. F., Markon, K. E., Borroni, S., \& Maffei, C. (2013). Reliability and validity of the personality inventory for DSM-5 (PID-5): Predicting DSM-IV personality disorders and psychopathy in community-dwelling Italian adults. Assessment, 20(6), 689-708. https://doi.org/10.1177/1073191113504984.

Fowler, J. C., Patriquin, M. A., Madan, A., Allen, J. G., Frueh, B. C., \& Oldham, J. M. (2017). Incremental validity of the PID-5 in relation to the five factor model and traditional polythetic personality criteria of the DSM-5. International Journal of Methods in Psychiatric Research, 26(2), e1526. https://doi.org/10.1002/mpr.1526.

Frances, A. (1993). Dimensional diagnosis of personality-not whether, but when and which. Psychological Inquiry, 4(2), 110-111. https:// doi.org/10.1207/s15327965pli0402_7.

Griffin, S. A., \& Samuel, D. B. (2014). A closer look at the lower-order structure of the personality inventory for DSM-5: Comparison with the five-factor model. Personality Disorders: Theory, Research, and Treatment, 5(4), 406-412. https://doi.org/10.1037/per0000074.

Gutiérrez, F., Aluja, A., Peri, J. M., Calvo, N., Ferrer, M., Baillés, E., Gutiérrez-Zotes, J. A., Gárriz, M., Caseras, X., Markon, K. E., \& Krueger, R. F. (2017). Psychometric properties of the Spanish PID-5 in a clinical and a community sample. Assessment, 24(3), 326-336. https://doi.org/10.1177/1073191115606518.

Hu, L. T., \& Bentler, P. M. (1999). Cutoff criteria for fit indexes in covariance structure analysis: Conventional criteria versus new alternatives. Structural Equation Modeling, 6(1), 1-55. https://doi. org/10.1080/10705519909540118.

Krueger, R. F., Derringer, J., Markon, K. E., Watson, D., \& Skodol, A. E. (2012). Initial construction of a maladaptive personality trait model and inventory for DSM-5. Psychological Medicine, 42(9), 18791890. https://doi.org/10.1017/S0033291711002674.

Lotfi, M., Bach, B., Amini, M., \& Simonsen, E. (2018). Structure of DSM-5 and ICD-11 personality domains in Iranian community sample. Personality and Mental Health, 12(2), 155-169. https://doi.org/ 10.1002/pmh.1409.

Marsh, H. W., Hau, K. T., \& Wen, Z. L. (2004). In search of golden rules: Comment on hypothesis-testing approaches to setting cutoff values for fit indexes and dangers in overgeneralizing $\mathrm{Hu}$ and Bentler's (1999) findings. Structural Equation Modeling, 11(3), 320-341. https://doi.org/10.1207/s15328007sem1103 2.

Ogasawara, H. (1998). Standard errors of several indices for unrotated and rotated factors. Economic Review, Otaru University of Commerce, 49(1), 21-69.

Pires, R., Sousa Ferreira, A., \& Guedes, D. (2017). The psychometric properties of the Portuguese version of the personality inventory for DSM-5. Scandinavian Journal of Psychology, 58(5), 468-475. https://doi.org/10.1111/sjop.12383.

Pires, R., Sousa Ferreira, A., Goncalves, B., Henriques-Calado, J., \& Paulino, M. (2019). The Portuguese version of the personality inventory for the DSM-5 in a community and a clinical sample. Personality and Mental Health, 13(1), 40-52. https://doi.org/10. 1002/pmh.1437.

Quilty, L. C., Ayearst, L., Chmielewski, M., Pollock, B. G., \& Bagby, R. M. (2013). The psychometric properties of the personality inventory for DSM-5 in an APA DSM-5 field trial sample. Assessment, 20(3), 362-369. https://doi.org/10.1177/1073191113486183.

Riegel, K. D., Ksinan, A. J., Samankova, D., Preiss, M., Harsa, P., \& Krueger, R. F. (2018). Unidimensionality of the personality inventory for DSM-5 facets: Evidence from two Czech-speaking samples. Personality and Mental Health, 12(4), 281-297. https://doi.org/10. 1002/pmh.1423.

Roskam, I., Galdiolo, S., Hansenne, M., Massoudi, K., Rossier, J., Gicquel, L., \& Rolland, J. P. (2015). The psychometric properties of the French version of the personality inventory for DSM-5. PLoS One, 10(7), e0133413. https://doi.org/10.1371/journal.pone.0133413.

RStudio Team. (2015). RStudio: Integrated development for R. Boston: RStudio Retrieved from: http://www.rstudio.com/.

Sleep, C. E., Hyatt, C. S., Lamkin, J., Maples-Keller, J. L., \& Miller, J. D. (2018). Examining the relations among the DSM-5 alternative model of personality, the five-factor model, and externalizing and internalizing behavior. Personality Disorders: Theory, Research, and Treatment, 9(4), 379-384. https://doi.org/10.1037/per0000240.

Strus, W., Rowiński, T., Cieciuch, J., Kowalska-Dąbrowska, M., Czuma, I., \& Żechowski, C. (2017). The pathological big five: An attempt to build a bridge between the psychiatric classification of personality disorders and the trait model of normal personality. Roczniki Psychologiczne, 20(2), 451-472. https://doi.org/10.18290/rpsych.2017.20.2-6en.

Suzuki, T., Samuel, D. B., Pahlen, S., \& Krueger, R. F. (2015). DSM-5 alternative personality disorder model traits as maladaptive extreme variants of the five-factor model: An item-response theory analysis. Journal of Abnormal Psychology, 124(2), 343-354. https://doi.org/ 10.1037/abn0000035.

Szentmiklósi, J. A. (2011). Az orvostudományi kutatások etikai engedélyezése: elméleti és gyakorlati szempontok. In Z. Bereczky \& L. Muszbek (Eds.), A klinikai kutatások tervezése és kivitelezése: elméleti és módszertani alapok (pp. 179-193). Budapest: Medicina Könyvkiadó Zrt.

Thimm, J. C., Jordan, S., \& Bach, B. (2017). Hierarchical structure and crosscultural measurement invariance of the Norwegian version of the personality inventory for DSM-5. Journal of Personality Assessment, 99(2), 204-210. https://doi.org/10.1080/00223891.2016.1223682.

Thomas, K. M., Yalch, M. M., Krueger, R. F., Wright, A. G., Markon, K. E., \& Hopwood, C. J. (2013). The convergent structure of DSM-5 personality trait facets and five-factor model trait domains. Assessment, 20(3), 308-311. https://doi.org/10.1177/1073191112457589.

Trull, T. J. (2012). The five-factor model of personality disorder and DSM-5. Journal of Personality, 80(6), 1697-1720. https://doi.org/ 10.1111/j.1467-6494.2012.00771.x.

Trull, T. J., \& Durrett, C. A. (2005). Categorical and dimensional models of personality disorder. Annual Review of Clinical Psychology, 1, 355380. https://doi.org/10.1146/annurev.clinpsy.1.102803.144009.

Van den Broeck, J., Bastiaansen, L., Rossi, G., Dierckx, E., De Clercq, B., \& Hofmans, J. (2014). Hierarchical structure of maladaptive personality traits in older adults: Joint factor analysis of the PID-5 and the DAPP-BQ. Journal of Personality Disorders, 28(2), 198211. https://doi.org/10.1521/pedi 201327114.

Watson, D., Stasik, S. M., Ro, E., \& Clark, L. A. (2013). Integrating normal and pathological personality: Relating the DSM-5 trait-dimensional model to general traits of personality. Assessment, 20(3), 312-326. https://doi.org/10.1177/1073191113485810.

Wright, A. G., Thomas, K. M., Hopwood, C. J., Markon, K. E., Pincus, A. L., \& Krueger, R. F. (2012). The hierarchical structure of DSM-5 pathological personality traits. Journal of Abnormal Psychology, 121(4), 951-957. https://doi.org/10.1037/a0027669.

Zimmermann, J., Altenstein, D., Krieger, T., Holtforth, M. G., Pretsch, J., Alexopoulos, J., Spitzer, C., Benecke, C., Krueger, R. F., Markon, K. E., \& Leising, D. (2014). The structure and correlates of selfreported DSM-5 maladaptive personality traits: Findings from two German-speaking samples. Journal of Personality Disorders, 28(4), 518-540. https://doi.org/10.1521/pedi 201428130.

Publisher's Note Springer Nature remains neutral with regard to jurisdictional claims in published maps and institutional affiliations. 